\title{
Gênero e participação em nível local: estudo sobre conferências municipais de políticas públicas
}

Revista de
Sociologia
e Política

DOI $10.1590 / 1678-987320287610$

\author{
Wagner Romão'iD e Carla Giani Martelli" \\ 'Departamento de Ciência Política, Instituto de Filosofia e Ciências Humanas, Universidade Estadual de Campinas, Campinas, \\ SP, Brasil. \\ "Departamento de Ciências Sociais, Faculdade de Ciências e Letras, Universidade Estadual Paulista "Júlio de Mesquita Filho", \\ Araraquara, SP, Brasil.
}

RESUMO Introdução: Este artigo pretende discutir a participação de mulheres nas conferências de políticas públicas no nível municipal. A literatura tem apontado que as conferências são modalidades de participação com potencial para diminuir as desigualdades de gênero próprias das instituições políticas tradicionais como o Poder Legislativo, nos três níveis de governo. No entanto, mesmo as conferências em seus níveis superiores (nacional e estadual), parecem reproduzir estas mesmas desigualdades. Buscamos compreender os elementos fundantes deste fenômeno ao analisar atributos de participantes de conferências em nível municipal, com foco nos diversos setores de políticas públicas e dos vínculos associativos destes participantes. Materiais e métodos: A pesquisa empírica se concentrou sobre sete conferências municipais ocorridas em 2013 na cidade de Piracicaba-SP, referentes aos setores de Educação, Assistência Social, Cidades, Meio Ambiente, Cultura, Identidade Racial e Esportes. Foram aplicados questionários aos participantes destas conferências, com o cuidado de não incluirmos dentre estes representantes do governo local. Obtivemos informações a respeito do perfil socio-econômico e político-institucional dos respondentes. Em seguida, procedemos à tabulação e ao tratamento estatístico dos dados obtidos, com a realização de teste qui-quadrado de independência, para verificarmos a existência de associação entre as variáveis analisadas e o tipo de conferência, e posterior análise de correspondências múltiplas, uma vez que desejávamos avaliar a associação entre variáveis categóricas. Resultados: Há uma forte associação entre participantes do sexo feminino e as conferências de Educação e Assistência Social. Este resultado está relacionado à atividade profissional das mulheres nestes setores, como professoras e assistentes sociais, reforçando a tese de que considerar a especificidade das áreas de políticas públicas é algo importante para a compreensão do potencial inclusivo das mulheres nas conferências. Para além disso, foi bastante significativa a não vinculação das mulheres com organizações não-governamentais, movimentos sociais, sindicatos e partidos políticos, assim como a não participação em conselhos e conferências anteriores. Discussão: A participação das mulheres em conferências municipais está fortemente relacionada a sua atividade profissional. A pouca presença das mulheres nas instituições e movimentos que organizam a sociedade civil, bem como nos partidos políticos - na comparação com os homens - são fatores que não apenas estão correlacionados, mas que considerados em conjunto, potencializam o cerceamento da participação das mulheres nas instâncias de decisão política da sociedade brasileira, inclusive nos espaços de participação institucional como as conferências, mesmo no nível local.

PALAVRAS-CHAVE: conferências de políticas públicas; gênero; participação; sociedade civil; governo local.

Recebido em 21 de Março de 2019. Revisado em 26 de Maio de 2020. Aceito em 26 de Julho de 2020.

\section{Introdução}

${ }^{1}$ As duas primeiras conferências realizadas no
$\mathrm{O}$ Brasil vivenciou uma explosão de experiências participativas a partir da redemocratização e sobretudo após a promulgação da Constituição de 1988. Desde então, diversas formas de participação social foram institucionalizadas. Orçamento participativo, conselhos, conferências, planos diretores e audiências públicas são algumas das diversas modalidades de participação que a literatura tem agrupado sob o conceito de instituições participativas (Avritzer, 2009).

O objeto deste artigo são as conferências de políticas públicas. As primeiras conferências conhecidas ocorreram na década de $1940^{1}$ e à época serviam como situações de reunião entre gestores públicos e especialistas para a promoção de 
Brasil foram a Conferência Nacional de Educação e a Conferência Nacional de Saúde, ambas em 1941 (BRASIL, 2009). articulação federativa e ampliação da racionalidade administrativa. Não são, portanto, fenômenos recentes. No entanto, o formato e os objetivos das conferências foram significativamente alterados ao longo do tempo. Inicialmente de caráter administrativo e técnico, a partir da década de 1980 as conferências passaram a ser grandes espaços de deliberação pública, com natureza marcadamente política. Com a Constituição de 1988, várias políticas públicas passaram a incluir as conferências nacionais como modalidades específicas dos seus sistemas participativos, como foi o caso paradigmático do Sistema Único de Saúde (SUS), logo replicado em diversas outras áreas (Avelino \& Goulin, 2018). De 1941 a 2016 foram realizados 154 processos conferenciais em mais de 40 áreas de políticas públicas. Dessas conferências, 34 aconteceram até 2002. Outras 75 conferências aconteceram nos governos Lula (2003-2010). Em suas diversas etapas presenciais e/ou virtuais, esses processos envolveram mais de 7 milhões de pessoas em todo o país. Outras 41 conferências foram organizadas pelo primeiro e segundo governo Dilma (2011-2016) (Bezerra, 2020, p.178).

Atualmente, as conferências podem ser definidas como amplos encontros participativos que reúnem setores sociais e governamentais para a discussão e apresentação de propostas e diretrizes em sua respectiva área de política pública. Esses encontros são previstos por lei e/ou por regimentos que determinam suas regras de composição, periodicidade e competência. Embora haja especificidades em cada área de política, em geral são convocadas pelo poder executivo com a participação de setores sociais organizados e de conselhos nacionais das áreas relativas à conferência. As conferências ocorrem de forma escalonada, iniciando na esfera municipal e progredindo, por meio da representação de delegados, para as etapas estaduais e nacional. Embora, em geral, não apresentem competência deliberativa, elas se constituem como espaços muito importantes para a formação de agenda de questões e demandas a serem incorporadas por instâncias governamentais. São, portanto, "mecanismos eficazes de canalização de demandas sociais e de avaliação da situação de serviços públicos, especialmente na etapa municipal" (Côrtes, 2011, p.140).

Estudos recentes têm analisado as conferências em sua etapa nacional, como mostra o trabalho organizado por Avritzer e Souza (2013), mas poucas pesquisas se dedicaram a explorar sistematicamente a etapa municipal. Menos ainda sob uma perspectiva comparada entre setores de políticas públicas. De maneira geral, sabe-se muito pouco sobre as relações entre as conferências e o poder local, as especificidades entre os setores de políticas públicas e as variações relativas ao público que as acessa.

Este artigo se propõe a contribuir com pesquisas sobre conferências de políticas públicas no plano local. Nossa metodologia combinou a estratégia do estudo de caso único com a comparação de $\mathrm{N}$ pequeno (Halperin \& Heath, 2012). Para nós importava concentrar nossas análises em um contexto sociopolítico que nos era relativamente conhecido - um município no qual já havíamos trabalhado em pesquisas anteriores (Morgado, Romão, Beitum \& Palmieri, 2013; Martelli, 2015; Martelli \& Romão, 2016) - e proceder a um estudo comparativo sobre as características dos participantes de conferências em distintos setores de políticas públicas. Nossa preocupação inicial era por identificar semelhanças e diferenças no perfil de participantes de cada conferência e buscar explicações para isso.

Assim, a base empírica de nosso estudo foi recolhida em conferências municipais em Piracicaba ao longo do ano de 2013. Obtivemos dados sobre participantes de sete conferências nos seguintes setores: assistência social, cultura, educação, igualdade racial, cidades, esporte e meio ambiente. Em cada 
uma destas conferências foram aplicados questionários com foco sobre o perfil socioeconômico e associativo de seus participantes.

Nossos achados empíricos nos levaram à reflexão sobre a participação das mulheres nas instituições participativas, especialmente nas conferências em nível local. Pela análise dos dados obtidos percebemos que, em primeiro lugar, a participação das mulheres aparece bastante vinculada à sua atuação profissional nas prefeituras, sobretudo quanto àquelas profissões referidas ao cuidado e à relação com crianças, como assistência social e educação, considerando que aos municípios recaem sobretudo as ações de educação infantil. Nas conferências destes setores, o que se verifica é uma participação bastante ligada à administração pública local, em geral referidas ao próprio funcionalismo e, especificamente na assistência social, às entidades da sociedade civil ligadas à execução dos serviços públicos.

Em segundo lugar verificamos que as participantes das conferências municipais apresentam menores chances de estarem ligadas à sociedade civil (movimentos sociais, organizações da sociedade civil e sindicatos) e também à sociedade política (neste estudo, os partidos políticos). Essa pode ser uma explicação para a diminuição da participação das mulheres nos níveis superiores das conferências, uma vez que de maneira geral cabe às lideranças da sociedade civil as delegações às conferências estaduais e nacionais.

Assim, considerando que as diferenças relacionadas a gênero no que toca à participação política são multicausais, nossa proposta neste artigo é explorar duas linhas principais de análise: por um lado, a importância do setor de política pública na definição de maior ou menor participação de homens e mulheres nas conferências; e, por outro lado, a relação entre gênero e vínculo associativo, seja à sociedade civil ou política.

Além desta introdução, este artigo se compõe de mais quatro tópicos. No segundo tópico, demonstraremos como a literatura tem lidado com a questão de gênero no debate sobre as instituições participativas. Mostraremos como, embora já se aponte o vínculo entre gênero e setor de política pública, ainda não se avançou na identificação das relações entre gênero e vínculo associativo. Isso impediu os trabalhos até aqui publicados de perceber as causas do "desaparecimento" das mulheres nos níveis superiores da arquitetura participativa, isto é, as conferências e conselhos estaduais e nacionais. No terceiro tópico, apresentaremos nossa metodologia de pesquisa, desde a produção dos questionários até o tratamento estatístico realizado. No quarto tópico apresentaremos a análise de nossos resultados mais relevantes, com ênfase em nossos achados relativos à questão de gênero. Por fim, apresentaremos nossas considerações finais esperando contribuir com os estudos sobre o potencial das conferências de políticas públicas para a inclusão de segmentos populacionais que têm estado em posição de subordinação de processos participativos, como as mulheres.

\section{Gênero e instituições participativas}

Uma das questões importantes no debate sobre instituições participativas diz respeito ao seu potencial de inclusão de segmentos populacionais que têm estado em posição de subordinação ou mesmo de exclusão em processos de participação política, como as mulheres, os negros, os analfabetos, os de baixa escolaridade e com menor renda (Cunha, 2013).

Não há consenso na resposta. Tanto é assim que na avaliação de Côrtes (2005) é possível identificar dois grupos de pesquisadores, sendo o primeiro deles constituído por autores que têm uma visão mais positiva sobre os possíveis efeitos das instituições participativas (Santos \& Avritzer, 2002), considerando serem estas instituições formas de exercício coletivo do poder público 
que favorecem a inserção de movimentos sociais em arenas políticas institucionalizadas, abrindo espaço para grupos sociais que ainda não conseguiram se fazer representar por meio dos parlamentos tradicionais. Como consequência da inclusão de novos atores sociais, alguns analistas chegaram a identificar possíveis efeitos democratizantes e (re)distributivos associados à atividade participativa (Santos, 1998; Marquetti, 2003). O segundo grupo elabora uma perspectiva mais crítica ao chamar atenção para o fato de que fóruns participativos tendem a ser ocupados, principalmente, por atores que têm condições de se organizar e possuem recursos financeiros e de poder. Para esse conjunto de autores (Fiorina, 1999; Pinto, 2004; Skocpol \& Fiorina, 1999), os grupos sociais, historicamente excluídos, continuariam sem acesso aos espaços decisórios, uma vez que os desenhos institucionais dos fóruns participativos tenderiam a reproduzir as desigualdades já existentes no ambiente social e político (Côrtes, 2005; Alencar et al., 2013).

Identificando a reprodução da desigualdade em fóruns participativos, algumas conferências asseguram cotas de representação para determinados grupos sociais, considerados historicamente excluídos dos processos de tomada de decisão pública no país, tais como as mulheres e os grupos étnico-raciais (Petinelli 2014).

Fazendo coro aos mais otimistas, alguns pesquisadores chamam atenção para outros dois aspectos que estariam contribuindo para alterar a visão de que os fóruns participativos necessariamente reproduzem desigualdades. É o caso de estudos (Lovenduski, 2005; Bohn, 2010; Avelar, 2013) que mostram que as ativistas feministas entraram na burocracia estatal não pelo sistema eleitoral, mas por meio da criação de secretarias, ministérios e órgãos especializados em políticas para mulheres expressando, portanto, uma forma específica de institucionalização da presença feminina no Estado e um canal particular de inclusão das demandas dos movimentos feministas no sistema político. Outro exemplo vem de estudos (Avelar, 2013; Zaremberg, 2016) que mostram as potencialidades de inclusão política de mulheres promovidas pelas inovações institucionais criadas nas últimas décadas em vários países da América Latina, como as instituições participativas no Brasil, os consejos municipales de desarrollo rural sustentable no México, os gabinetes de participación ciudadana na Nicarágua e os consejos comunales na Venezuela.

Acompanhando esse viés mais positivo, Lüchmann e Almeida (2010), em pesquisa sobre conselhos municipais em Santa Catarina, também observam que se na esfera da representação política eleitoral a balança registra peso altamente favorável para os homens, essa balança pode pender em favor das mulheres quando consideradas outras instâncias participativas, como é o caso dos conselhos gestores de políticas públicas, sobretudo em se tratando de conselhos da área social, tradicionalmente reconhecida como um terreno de atuação feminina, dada a associação socialmente construída das mulheres à esfera da reprodução e dos homens à esfera da produção. A presença de maior número de mulheres nos conselhos das áreas sociais pode estar associada, em parte, à concepção sobre sua suposta competência intrínseca para os temas enquadrados como sociais e sua ética pautada nos princípios da "solidariedade" e "sensibilidade", que seriam o substrato da lógica de atuação política nos conselhos, de acordo com entrevistas realizadas junto às próprias conselheiras. As atividades voltadas aos cuidados da vida doméstica registram diferentes responsabilidades e recursos nas relações de gênero, resultantes dos processos históricos de socialização que conduziram, de forma dramática, à configuração do monopólio masculino de apropriação do território da política. A persistente ausência ou subrepresentação das mulheres nas posições de poder deve-se, em larga medida, à associação entre o feminino e o espaço doméstico, e entre o masculino e o espaço da grande política - o espaço da competição e da liderança para a 
alocação autorizativa dos recursos da sociedade (Conway; Steuernagel \& Ahern, 2005, apud Lüchmann \& Almeida, 2010, p.87).

Outro exemplo, ainda relacionado a conselhos, vem de uma grande pesquisa realizada por Alencar et al. (2013) sobre o perfil de conselheiros nacionais (767 respondentes). Com o objetivo de investigar se as relações de desigualdades sociais e políticas, tradicionalmente manifestas entre pessoas de diferentes regiões, classe, cor/raça e sexo também se verificam nos conselhos nacionais, o trabalho examina informações sobre o perfil dos conselheiros nacionais, em contraste com dados socioeconômicos e demográficos da população brasileira e com dados sobre perfil dos representantes políticos no Congresso Nacional. Os conselhos nacionais foram divididos em quatro áreas temáticas: políticas sociais; garantia de direitos; desenvolvimento econômico; infraestrutura e recursos naturais. Considerando a variável sexo, os achados da pesquisa mostram que os conselhos nacionais possuem uma composição predominantemente masculina - cerca de $63 \%$ de homens e $37 \%$ de mulheres. No entanto, essa proporção varia de acordo com a temática do conselho, por exemplo, os conselheiros dos conselhos voltados para políticas sociais e garantia de direitos possuem uma divisão mais equitativa - na qual a quantidade de homens ou mulheres varia de $40 \%$ a $60 \%$ - nos demais, a quantidade de homens supera os $70 \%$. A partir dessas informações, foi possível verificar que o perfil social dos conselheiros é marcado por predominância do sexo masculino, cor/raça branca, renda e escolaridade acima da média da população brasileira. Em alguns casos, observa-se mesmo a reprodução de determinados perfis desiguais da população brasileira nesses espaços. Vale perceber que, apesar da relativa uniformidade em relação aos dados de renda e escolaridade, existem diferenças entre o perfil de alguns conselhos, como se pode verificar, por exemplo, por meio de maior potencial de inclusão nos conselhos de proteção social, em especial conselhos de garantias de direitos (Alencar et al., 2013, p.137-8).

Em estudo sobre as conferências estaduais de Minas Gerais, Cunha (2013) observou variação de participação de homens e mulheres a depender do tipo de política. Por exemplo, observou forte presença feminina na conferência estadual de assistência social, acima do percentual da população em geral, que estaria possivelmente relacionada à sua trajetória, fortemente identificada com as mulheres, como trabalhadoras e como usuárias, diferentemente de outras áreas temáticas, como ciência e tecnologia, fortemente marcadas pela presença masculina. Assim, a autora destaca a importância da dependência da trajetória para a compreensão da participação política de homens e mulheres (Cunha, 2013, p.157). Dados do IPEA (2013) também registram que a participação feminina entre titulares das secretarias estaduais de assistência social é maior que em outras pastas, totalizando 13 das 27 unidades da Federação, o que corresponde a $48 \%$ dos gestores estaduais. No que se refere à gestão municipal, a predominância é feminina: em $17,7 \%$ dos municípios que declararam ter órgão gestor de assistência social, os dirigentes dessa pasta são homens, enquanto que, em 82,2\%, são mulheres. Destas, $23 \%$ são as esposas de prefeitos, conforme Lüchmann et al. (2016, p.796). O fenômeno se reproduz na esfera participativa. As autoras também apontam - após estudo sobre 140 conselhos gestores ( 3 federais, 32 estaduais e 105 municipais) nas áreas de assistência social, saúde e meio ambiente - que há uma acentuada predominância feminina na área de assistência social, quando comparada às pastas da saúde (na qual verifica-se um maior equilíbrio entre homens e mulheres) e do meio ambiente (onde há predomínio de homens).

Assim, independentemente da instituição participativa - se conselhos ou conferências - o setor de política importa para explicar maior ou menor participação das mulheres nesses espaços. Uma outra variável que tem sido apontada como importante para compreender a maior ou menor participação 
${ }^{2}$ Esta naturalização dos papeis é lembrada por Conway (2001, p.233) ao falar na construção de "estereótipos de gênero" (gender stereotypes), referindo-se à escolha do público nas eleições dos Estados Unidos. Às mulheres são reservadas as questões domésticas, como educação e bem-estar da família, enquanto os homens são vistos como melhores para lidar com temas políticos, de finanças, de política internacional e segurança nacional. feminina em fóruns participativos é a que diz respeito ao nível de governo (municipal, estadual ou federal). Os dados da pesquisa realizada por Faria et al. (2019, p.365) com as conferências municipais de saúde, assistência social e políticas para as mulheres em Belo Horizonte mostram que o perfil dos participantes (não só em relação a gênero, mas também considerando idade, raça, escolaridade, renda e perfil participativo) varia de forma mais significativa considerando o nível territorial, e menos a área de política. Ou seja, mais que a área de política, importa a mudança de escala .

Considerando a variável gênero, pesquisas têm demonstrado que as instituições participativas em nível municipal agregam maior participação de mulheres do que nos níveis nacionais. Em estudo sobre conferências de políticas públicas, Cunha (2013) verificou que a participação das mulheres decresce conforme aumenta a escala, ou seja, mais no nível municipal que no estadual e nacional. Para a autora, isto pode estar ligado ao fato de que as mulheres tenham dificuldade de conciliar suas "tarefas do cotidiano" com a representação nos níveis superiores - que implicam distanciamento no tempo e no espaço. As dificuldades aumentam quando não há o aporte de apoios que viabilizem esta participação, como creches ou serviços de cuidadores para as crianças nos locais das conferência ou no financiamento de estadia para as crianças que demandam cuidados especiais ${ }^{2}$.

Aprofundando a análise sobre a influência do fator escala, Lüchmann, Almeida e Gimenez (2016) destacam que a intensidade de sua influência sofre variações a depender do segmento: se sociedade civil ou governo. Estudando os conselhos gestores nas áreas de assistência social, meio ambiente e saúde, nos três níveis de governo, observaram que na assistência social, conforme aumenta a escala, a diferença entre mulheres e homens diminui na sociedade civil, enquanto que no governo a representação de mulheres continua bem maior. $\mathrm{Na}$ saúde, a presença dos gêneros é relativamente equilibrada nos municípios tanto no segmento governamental como no da sociedade civil. Nos conselhos estaduais, para o segmento governamental, esse equilíbrio se mantém, com pequena vantagem para as mulheres, mas para o segmento da sociedade civil a pequena vantagem se inverte para os homens. Já no conselho nacional dessa área, os homens predominam nos dois segmentos. Na política de meio ambiente, desde o nível municipal, há predominância masculina, mas que se acentua na escala nacional, sobretudo na representação da sociedade civil. Ou seja, apesar das variações por área, percebe-se um movimento mais geral de ampliação da representação masculina conforme se avança na escala. Para explicar esses dados, chamam a atenção para o fato de que os custos da participação são maiores para a representação da sociedade civil, recaindo com maior intensidade no grupo das mulheres, a quem é atribuída a maior parte dos cuidados com as dimensões domésticas. Além disso, mostram que mesmo sendo maioria na base de algumas organizações, como meio ambiente, as mulheres são minoria nas cadeiras dos conselhos dessa área. Os homens acabam assumindo cargos de direção e representação até porque possuem mais recursos de tempo para experimentar e ganhar aprendizado para as responsabilidades que demandam esses cargos. Mas o principal problema, explicam os pesquisadores, "é que essa cadeia - mais tempo, mais recursos, mais experiência - se naturaliza na ideia de que os homens são mais preparados para cargos de direção. Em muitos casos, mesmo acumulando, a custos bem maiores, a mesma experiência e aprendizado, as mulheres são preteridas para esses cargos diretivos por conta daquela naturalização" (Lüchmann, Almeida \& Gimenez, 2016, p.815). Aliás, em artigo sobre associativismo e representação política feminina na Câmara dos Deputados, as mesmas autoras - desta vez com Ribeiro (Almeida, Lüchmann \& Ribeiro, 2012), percebem que há uma significativa presença de vínculos associativos nas carreiras das deputadas. Isto é, as carreiras bem sucedidas de mulheres na 
política se articulam ao associativismo - cujos lugares de destaque, geralmente são monopolizados por homens.

Não há uma única fonte de explicação para as diferenças de participação política entre homens e mulheres. Lüchmann e Almeida (2010), além de registrarem o fato de que as áreas sociais são tradicionalmente consideradas femininas, sugerem que a significativa presença feminina nos conselhos de políticas públicas está relacionada, também, à inovação trazida por estas instituições quanto aos procedimentos de escolha de representantes e aos significados específicos que são atribuídos a este tipo de representação, se comparados à representação eleitoral. Ou seja, as autoras estão chamando a atenção para as várias causas que podem explicar a menor ou maior presença das mulheres em instâncias da política. É por essa perspectiva que se referem ao trabalho de Phillips (1991) ao falar que a invisibilidade das mulheres na política, em suas instâncias tradicionais, deve ser entendida a partir de uma perspectiva multicausal, na medida em que processos de socialização e de constrangimentos culturais caminham lado a lado com os processos e constrangimentos políticoinstitucionais, como sistemas eleitorais, conformação dos partidos políticos e legislação (Lüchmann \& Almeida, 2010, p.88).

Em trabalho já citado, as autoras reforçam a importância do cruzamento de variáveis explicativas para a configuração das diferenças nos dados sobre a presença de mulheres e homens nos conselhos, propondo considerar, além da escala e da área de atuação dos conselhos, os respectivos desenhos institucionais e o tipo de associativismo que dá suporte à representação conselhista. No caso do desenho institucional, sugerem que pode fazer diferença se a escolha do conselheiro/a ocorre por meio de fóruns abertos da sociedade civil ou se é uma representação predefinida em regimentos, ou, ainda, resultante de indicação por outro segmento, como ocorre na área ambiental. Observam que, embora possa haver interveniência de outros fatores, a maior presença feminina nas organizações da sociedade civil, indica maiores oportunidades de inclusão feminina quando o processo de escolha ocorre no interior deste campo. Ou seja, mostram que faz diferença o tipo ou o perfil das organizações e instituições (tanto governamentais como sociais) que ocupam assento nos conselhos. Também mostram que, embora seja cada vez mais frequente a participação feminina em sindicatos e associações econômicas e políticas, permanece ainda muito forte o vínculo com organizações sociais relacionadas com o mundo familiar, comunitário e religioso, diferente do vínculo associativo masculino, mais próximo da esfera política institucional, do mundo do trabalho e do lazer (Lüchmann, Almeida \& Gimenez, 2016, p.811).

A não vinculação das mulheres com o associativismo se explica pela divisão sexual do trabalho. "A divisão sexual do trabalho doméstico implica menor acesso das mulheres a tempo livre e a renda, o que tem impacto nas suas possibilidades de participação política e nos padrões que essa participação assume" (Biroli, 2016, p. 721). Ou seja, a divisão sexual do trabalho consome tempo desigualmente de mulheres e homens. Isso ocorre também no que diz respeito às atividades do cuidado às pessoas em situação de dependência idosas, crianças, doentes ou pessoas com deficiência - realizadas tradicionalmente e gratuitamente na esfera doméstica e familiar pelas mulheres (Hirata, 2020). Quanto mais envolvidas estão as mulheres com o trabalho doméstico, menores as chances de acesso a movimentos e espaços de organização coletiva, menores as possibilidades de se envolverem com militância, sindicatos, partidos políticos etc., diminuindo, consequentemente, suas chances de lutarem contra as hierarquias, a opressão e as desvantagens que vivenciam (Biroli, 2016).

O exercício do trabalho não remunerado, dentro de casa, bem como o acesso ao trabalho remunerado se dá de forma diferenciada não apenas entre homens e 
mulheres, mas para diferentes grupos de mulheres. Biroli (2016, p.746) se refere a "opressões cruzadas", dada a convergência entre gênero, classe e raça. Ou seja, as assimetrias entre mulheres e homens permanecem, mas se definem em conjunto com as variáveis de classe e de raça. Assim, as mulheres, sobretudo as negras e as mais pobres, têm menos poder para politizar suas necessidades e interesses, pois encontram-se em desvantagem com relação aos grupos que detêm recursos para fazer valer os seus direitos junto ao Estado e no debate público.

No próximo tópico, demonstraremos como pretendemos nos inserir neste debate sobre as características da representação de mulheres em processos participativos, sobretudo no nível municipal, envolvendo setores diversos de políticas públicas.

\section{Metodologia}

\section{III.1 A pesquisa de campo}

A proposta inicial de nossa pesquisa era explorar as diferenças entre os públicos presentes nas conferências, na comparação entre determinados setores de políticas públicas. Naquele ano de 2013, em que recolhemos os dados primários, vivíamos ainda um período de alta intensidade de utilização desta forma de participação social. Realizávamos um projeto de extensão ${ }^{3}$ em Piracicaba e havia a expectativa da realização de sete conferências municipais na cidade, articuladas à realização de conferências em âmbito estadual e nacional. Com uma equipe de apoio ${ }^{4}$ aplicamos questionários e testamos a ideia que passamos a construir após alguns anos de pesquisa sobre conselhos e conferências: o perfil dos participantes da sociedade civil - e, portanto, suas características de gênero, étnicas e de vínculos associativos - teria forte correlação com o modo como os setores de políticas públicas se estruturam.

Este artigo, portanto, está construído sobre o que consideramos o principal achado daquela pesquisa empírica: a articulação entre desigualdade de gênero e desigualdade de acesso ao mundo associativo e a forma como isso afeta e limita a participação de mulheres em processos participativos pouco regulados e, em tese, abertos.

Os questionários foram aplicados por nossa equipe de pesquisadores de campo. O procedimento era o de distribuição dos questionários aos participantes no momento do credenciamento e posterior recolhimento, com o cuidado de que não fossem inquiridos os representantes do governo local.

Foram respondidos 407 questionários, com a distribuição indicada na Tabela 1. Para o perfil socioeconômico foram feitas perguntas fechadas considerando as seguintes variáveis: gênero, idade, raça/cor, escolaridade e renda. Para o perfil associativo foram feitas perguntas com relação à vinculação a ONGs/entidades, movimentos sociais, partidos políticos, sindicatos e participação em conselhos e conferências anteriores ${ }^{5}$.

\section{III.2 O tratamento estatístico}

\footnotetext{
5 A diferenciação entre ONGs/Entidades e movimentos sociais não é estanque na literatura. Para os fins deste estudo, a partir da declaração do respondente, fizemos uma checagem da organização mencionada.
}

Após a identificação da frequência geral e do cruzamento entre cada uma das variáveis (gênero, idade, raça/cor, escolaridade, renda, vínculo a ONG/entidades, vínculo a movimentos sociais, filiação partidária, vínculo a sindicato, participação em conselhos e em outras conferências) realizamos o teste estatístico Qui-Quadrado de independência, para verificarmos a existência de associação entre as variáveis analisadas e o tipo de conferência. Como na maioria das vezes as condições de aplicação do teste Qui-Quadrado não são satisfeitas, 
Tabela 1 - Credenciados e respondentes nas conferências pesquisadas

\begin{tabular}{lcccccccc}
\hline & $\begin{array}{c}\text { Assistência } \\
\text { Social }\end{array}$ & Cultura & Educação & $\begin{array}{c}\text { Igualdade } \\
\text { Racial }\end{array}$ & Cidades & Esporte & $\begin{array}{c}\text { Meio } \\
\text { Ambiente }\end{array}$ & Total \\
\hline Credenciados & 169 & 135 & 340 & 110 & 111 & 35 & 151 & 1.051 \\
Respondentes & 47 & 27 & 88 & 66 & 72 & 19 & 88 & 407 \\
\hline
\end{tabular}

Fonte: Elaboração própria.

${ }^{6}$ Agradecemos o apoio de Alexandre Cristóvão Maiorano no tratamento estatístico dos dados em nossa pesquisa.

${ }^{7}$ Para a análise de correspondências múltiplas ver Greenacre (1994). usamos o método estimação de Monte Carlo para obtenção do p-valor exato do teste. Este método é baseado no processo de reamostragem de um conjunto de tabelas de referências, com as mesmas dimensões das linhas e colunas das tabelas observadas, e fornece um meio para a obtenção de resultados precisos quando os dados não cumprem as condições necessárias para obtenção de resultados confiáveis usando o método padrão. Sendo assim, em todos os testes foram usadas 10 mil reamostras da verdadeira tabela analisada ${ }^{6}$.

Em seguida, como desejávamos avaliar a associação entre variáveis categóricas, realizamos análise de correspondências. Desta maneira, pudemos observar conjuntamente toda a informação contida em uma tabela de contingência, representando graficamente a estrutura de correlações, resultados esses que não seriam possíveis caso fossem feitas análises de variáveis duas a duas. Como se trata do cruzamento de mais que duas variáveis, trata-se de uma análise de correspondências múltiplas $(\mathrm{ACM})^{7}$.

Como resultado, a ACM apresenta um gráfico com as categorias analisadas, sendo que a análise de correspondência múltipla deve ser feita da seguinte maneira: cada ponto é relativo a uma categoria de determinada questão, sendo que categorias próximas no gráfico são mais correlacionadas do que as categorias mais distantes. Na prática, se duas categorias de questões diferentes estão próximas, a maioria de indivíduos que escolheu uma delas também optou pela outra. Isso foi importante pois nosso objetivo era relacionar as variáveis analisadas de forma que todas fossem consideradas em apenas uma análise.

Como observado na Tabela $1 \mathrm{~A}$, no apêndice deste artigo, apenas 0,98\% dos respondentes não responderam à pergunta relativa ao gênero, $1,97 \%$ à idade $\mathrm{e}$ $1,47 \%$ à escolaridade. Verificamos também que apenas $5,16 \%$ dos respondentes têm ensino fundamental e que $4,18 \%$ é de outra raça ou não apresentou informação sobre a cor. Assim, para podermos gerar categorias binárias, removemos os indivíduos que não possuíam informação a respeito de gênero, idade e escolaridade e criamos duas novas variáveis a partir da escolaridade e raça/cor, a saber, cor branca (Sim ou Não) e Ensino superior (Sim / Não)

No total, com a exclusão dos indivíduos citados anteriormente foram consideradas informações de 391 conferencistas. A partir da análise de correspondências múltiplas verificamos que a primeira dimensão (ajustada) explica $55,9 \%$ da inércia total modificada e que a segunda dimensão explica $12,3 \%$. Dessa forma, as duas primeiras dimensões explicam conjuntamente 68,2\% da associação (como uma medida da inércia total) que existe entre as categorias de análise. Para o ajuste da inércia foi considerada a correção de Benzécri (Benzécri, 1979).

Por fim, obtivemos a síntese gráfica da pesquisa (representada por meio do cruzamento entre primeira e segunda dimensão da análise de correspondências múltiplas, que será discutida a seguir) que mostra o cruzamento entre as duas dimensões analisadas. Ela mostra a associação entre as categorias presentes na análise, sendo que quanto mais próximas as classes estão, maior a presença de associação, e categorias que estão ao centro tendem a não estarem associadas a 
alguma outra. As coordenadas para o cruzamento estão dispostas no apêndice deste artigo.

\section{Resultados}

Passamos agora à exposição dos nossos principais achados. A Tabela 1A (no apêndice) apresenta a caracterização da amostra de acordo com as variáveis analisadas. As conferências com maiores frequências foram Educação e Meio Ambiente (88 casos, ou 21,62\% em ambas), seguido de Cidades (17,69\%, ou 72 casos), Igualdade Racial (16,22\%, ou 72 casos), Assistência Social (11,55\%, ou 47 casos), Cultura (6,63\%, ou 27 casos) e Esporte (4,67\%, ou 19 casos). Estes são os percentuais de cada conferência em nossa amostra geral.

Em geral, verificamos que a maioria dos conferencistas é do gênero feminino $(62,90 \%)$ e de cor branca $(66,58 \%)$. Além disso, maior parte tem idade entre 40 e 53 anos (32,19\%), seguido de 27 e 40 anos $(28,50 \%)$ e até 27 anos $(20,15 \%)$ e que cerca de $17 \%$ tem acima de 53 anos. Avaliando a escolaridade constatamos que a maioria tem ensino superior $(64,13 \%)$ e com relação à renda, verificamos que dividem-se principalmente entre as categorias analisadas, com maior frequência para a faixa entre 5 e 10 salários (25,80\%). Quanto ao vínculo a ONG e entidades, participação em movimentos sociais, filiação partidária, sindicato e conselhos temos que a maioria não possui vínculo. Para a variável de participação em outras conferências, também observamos maior proporção de participantes que assinalaram a opção de não participação $(56,51 \%)$, porém com menor discrepância e comparação com as variáveis anteriores.

Descritos os resultados gerais, destacamos alguns dos elementos mais marcantes na diferenciação entre as conferências que dizem respeito à relação entre conferências e gênero dos participantes e seus vínculos associativos (Gráfico 1).

O Gráfico 1 confirma as singularidades das áreas de políticas públicas para avaliação dos resultados: há presença massiva de mulheres nas áreas de assistência social e educação, onde elas formam a quase totalidade das pessoas presentes. Conforme Lüchmann e Almeida (2010), a participação política feminina, tradicionalmente, está associada às áreas que lidam mais com o tema do cuidado, como é o caso dos conselhos relacionados a políticas sociais. Isto é fortemente percebido na conferência de Assistência Social e, um pouco menos, mas com $92 \%$ de presença feminina, na conferência de Educação.

Por outro lado, com relação à escala, as conferências municipais aqui estudadas relativizam os achados das pesquisas citadas que apontam uma maior participação das mulheres no nível local, tendendo a decrescer conforme au-

Gráfico 1 - Relação entre tipo de conferências e gênero

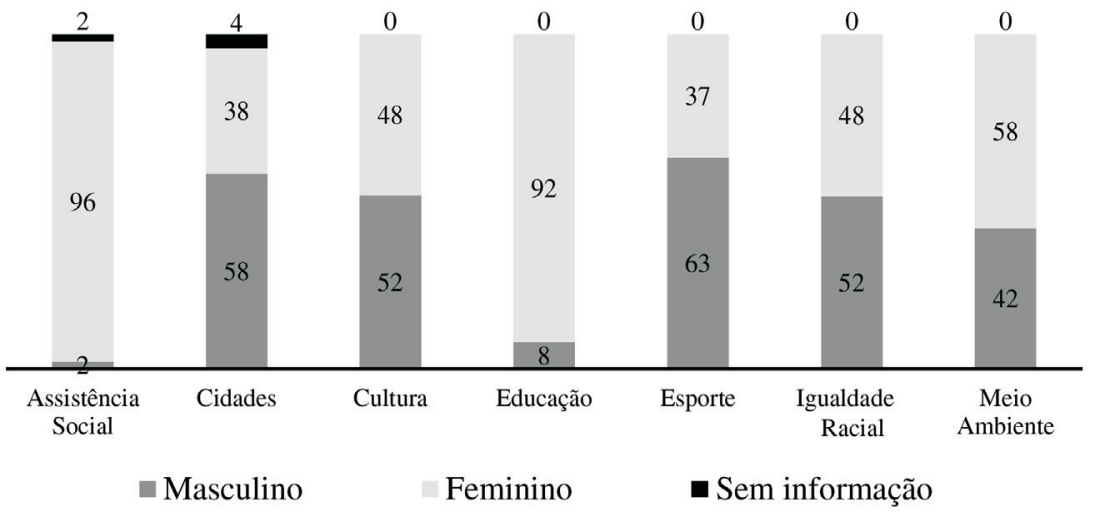

Fonte: Elaboração própria. 
menta a escala. Com exceção das conferências da Assistência Social e da Educação, e da conferência do Meio Ambiente com 58\% de mulheres, constatou-se maior presença masculina nas conferências do Esporte e de Cidades e certo equilíbrio de gênero nas conferências da Igualdade Racial e Cultura.

Será possível verificarmos a existência de algum tipo de correlação entre esta expressa diferenciação de gênero e algo sobre o perfil associativo das pessoas participantes? Analisaremos no Gráfico 2 as informações referentes a este aspecto e, como veremos, será possível sim identificar algo a este respeito.

Em geral, verifica-se que há cerca $40 \%$ de participação de conferencistas em entidades ou ONGs. Esta média sobe quando se trata da conferência do Esporte, com 53\% de participantes vinculados a alguma entidade, seguida das Cidades, com $44 \%$ e da Igualdade Racial, com $38 \%$. Na conferência da Educação, em que predominam participantes mulheres, encontramos a menor vinculação a ONGs ou entidades, com apenas 6\%. Pela característica da política de Assistência Social - com considerável mediação de entidades na oferta dos benefícios - e de seus processos participativos, a conferência do setor alcança $26 \%$, com presença de entidades religiosas, como a Pastoral do Serviço da Caridade PASCA e a Pastoral da Criança e, com frequência ainda maior, entidades que possuem convênios com a Prefeitura, como o Centro Regional de Registros e Atenção aos Maus Tratos na Infância, a Fundação Jaime Pereira e o Centro Social de Assistência e Cultura São José. Vejamos agora se existe relação entre tipo de conferência e o vínculo a movimento social (Gráfico 3).

À exceção da conferência de Cultura, que teve maioria de participantes vinculados a movimentos sociais (59\%), as outras conferências apresentaram

Gráfico 2 - Relação entre tipo de conferência e ser ou não ser vínculado a ONG/Entidade

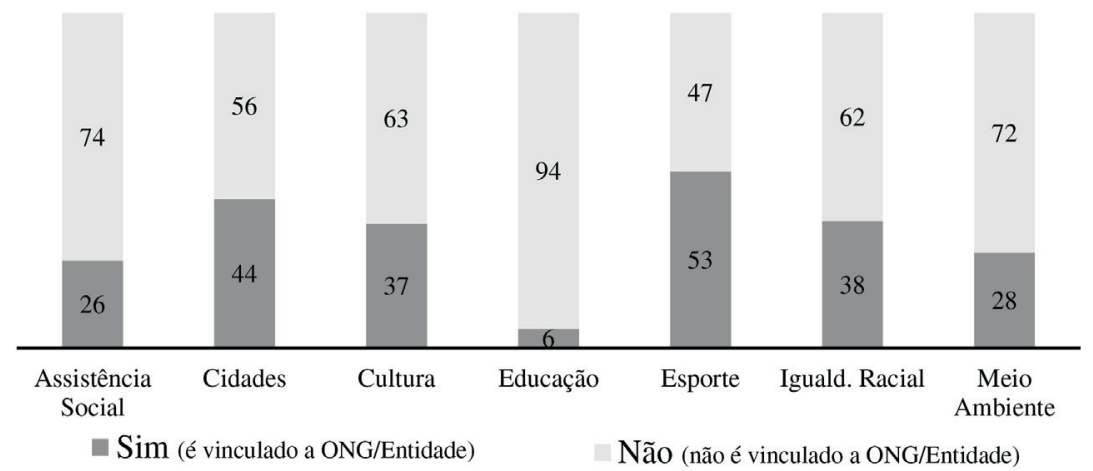

Fonte: Elaboração própria.

Gráfico 3 - Relação entre tipo de conferência e vínculo a movimento social

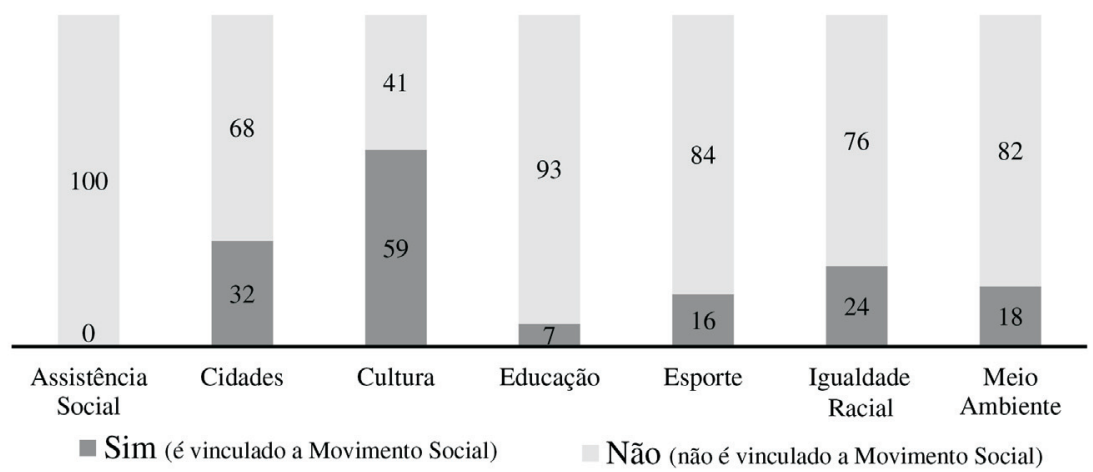

Fonte: Elaboração própria. 
índices relativamente baixos de vínculo. Os mais baixos índices foram das conferências de Educação (7\%) e de Assistência Social, onde nenhum participante declarou vínculo a movimentos sociais.

Na conferência das Cidades houve uma forte participação dos movimentos ligados à temática urbana Reaja Piracicaba e Pula Catraca, bem como também movimentos mais amplos como o movimento LGBT, jovem e de mulheres. Na Cultura, houve um misto de grupos culturais ou ligados diretamente às políticas culturais (Grupo Samba Rock de Ponta, Teatral Paixão de Cristo, Curto Circuito, Fórum do Teatro do Interior, Casa do Hip Hop, entre outros) e movimentos mais amplos (Movimento LGBT, Movimento Negro, Reaja Piracicaba, Pula Catraca). No caso da Educação, as poucas menções se referem às pastorais da igreja Católica. Na conferência de Esporte, apenas menções ao movimento estudantil. Quanto à conferência de Identidade Racial, encontramos menção ao Movimento Negro da cidade, a um grupo de capoeira (Cativeiro) e a grupos ligados às religiões de matriz africana. E na conferência de Meio Ambiente as menções mais frequentes foram ao movimento Reaja Piracicaba e ligados à educação ambiental. Vejamos agora se existe relação entre tipo de conferência e o vínculo a partidos políticos (Gráfico 4)

Quanto ao vínculo de participante das conferências a partidos políticos, apresentam-se baixos índices - à exceção das conferências das Cidades, Esporte e Igualdade Racial. Os índices são baixíssimos especialmente nas conferências de Assistência Social e Educação - predominantemente ocupadas por mulheres - e na de Meio Ambiente, relativamente com alto número de participantes jovens. Verifica-se que a maior parte dos participantes filiados a partidos é peessedebista, partido que governa a cidade de Piracicaba desde 2005: entre os filiados, $33 \%$ são do PSDB; $23 \%$ do PT; $11 \%$ do PV. Nenhum dos demais partidos alcançou mais que $7 \%$ de participantes, mas foi possível detectar a participação de filiados ao PR, PP, PDT, PPS, PTB, PCdoB, PSC, PMDB e PSOL.

Os dados mostram alta variação com relação à filiação a partidos políticos e indicam necessidade de trabalhos que levem em conta essa variável de maneira a se investigar a especificidade de cada setor de política pública e da representação da sociedade civil em cada um deles. Percebemos que em casos de alta filiação há variações que dizem respeito ao próprio amadurecimento desses espaços como expressões do conflito político no setor, com considerável diversidade de filiações partidárias e presença de partidos oposicionistas - como na conferência de Cidades - ou na menor diversidade e na ausência de filiados a partidos oposicionistas, como na conferência de Esporte, ao menos no caso de Piracicaba, fortemente vinculada ao próprio governo. O mesmo raciocínio pode

Gráfico 4 - Relação entre tipo de conferência e vínculo a Partido Político

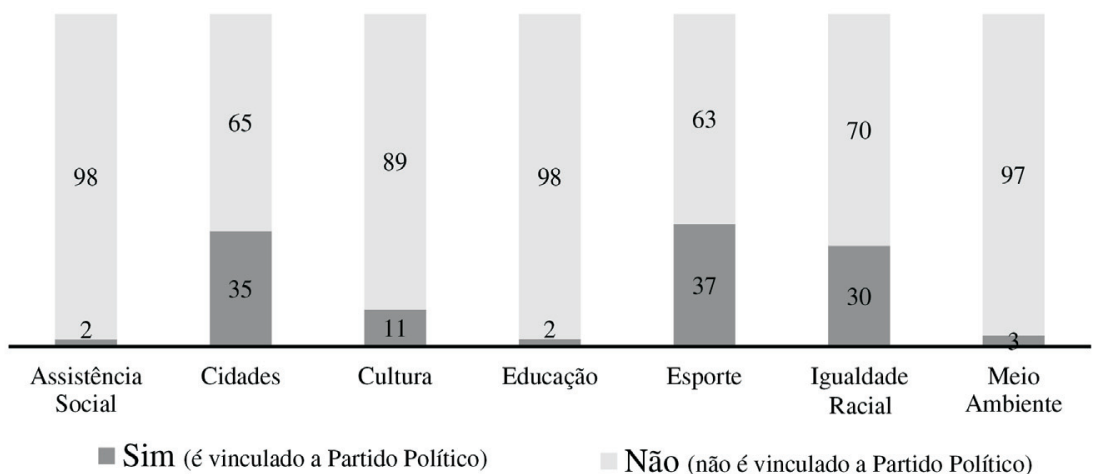

Fonte: Elaboração própria. 
se aplicar com relação às variações sobre os vínculos dos participantes a sindicatos e movimentos sociais.

Como já indicamos, a Figura 1 mostra a associação entre as categorias presentes na análise, sendo que quanto mais próximas as classes estão, maior a presença de associação, e categorias que estão ao centro tendem a não estarem associadas a alguma outra. A Figura 1 consolida as relações entre as conferências e as variáveis trabalhadas ao longo deste artigo, e é o resultado chave da análise e para construí-lo consideramos as coordenadas exibidas nas Tabelas 2A e 3A (no apêndice deste artigo).

Gostaríamos de chamar a atenção do leitor às variáveis de sexo, especialmente ao "feminino". O que se pode depreender pela análise da figura é a relevante associação entre sexo feminino e sua proximidade às conferências de Educação e Assistência Social - como já demonstramos nos gráficos anteriores. Ressaltamos que esta forte presença está relacionada à própria atividade profissional das mulheres nos setores, como professoras e assistentes sociais. De certo modo, este resultado já era esperado, pelo que mostrou a literatura analisada.

Parece-nos ainda mais significativa a não vinculação das mulheres com o mundo institucional, no contexto da sociedade civil. De maneira geral, na comparação com os homens, elas são muito menos vinculadas a ONGs, movimentos sociais, sindicatos e partidos políticos. Também participam menos de conselhos e participaram menos de conferências anteriormente. Ou seja, praticamente todas as filiações a entidades e outros tipos de participação obtém índices baixos, mas entre as mulheres este índice é muito mais baixo quando comparado a pessoas do sexo masculino.

Figura 1 - Cruzamento entre primeira e segunda dimensão da análise de correspondências múltiplas

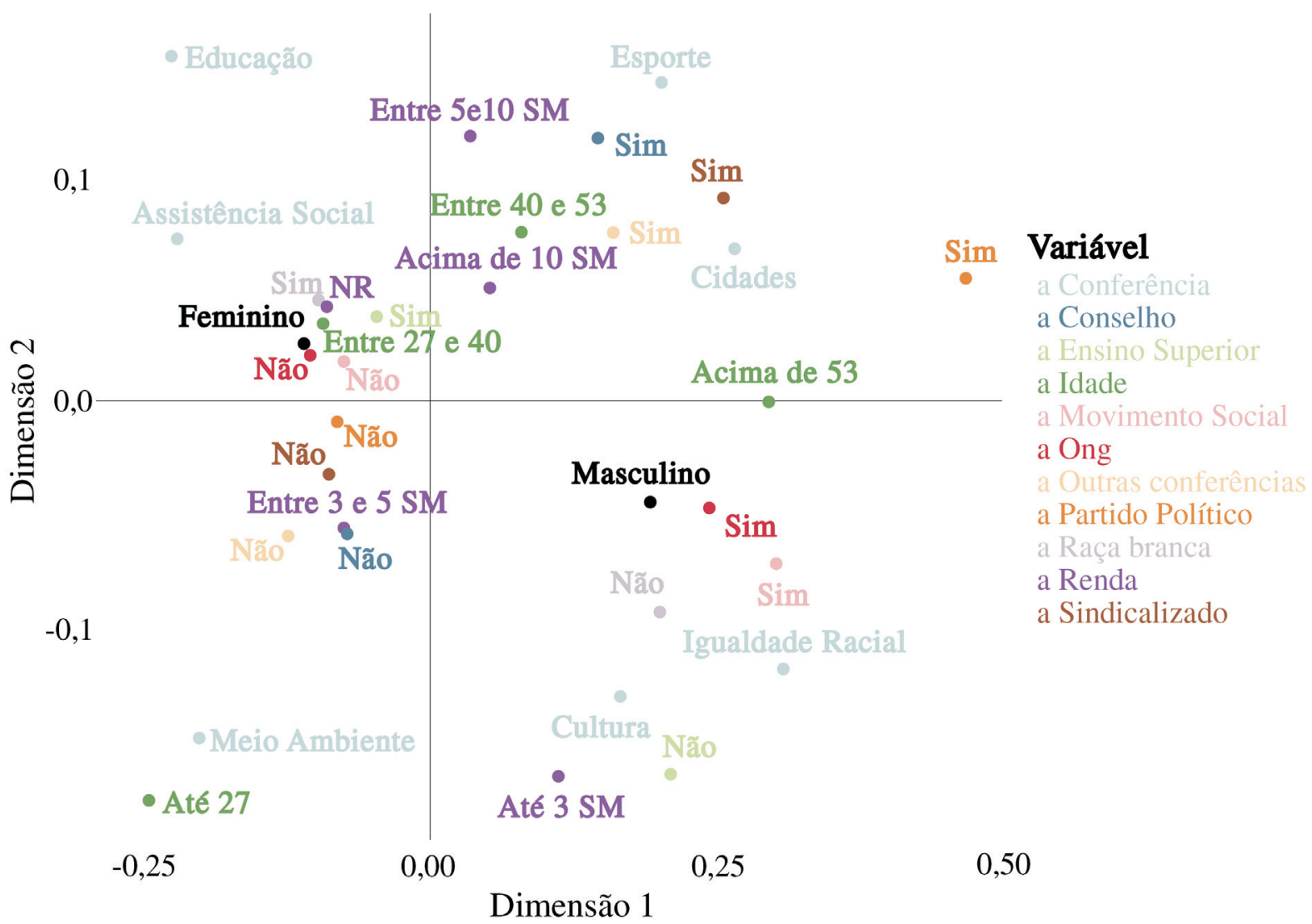

Fonte: Elaboração própria. 


\section{Considerações finais}

${ }^{8}$ Conforme Romão (2011) apresenta em seu estudo sobre as experiências de Orçamento Participativo.
A maior ausência em conselhos e em conferências anteriores - agregada à maior ligação dos homens à sociedade civil e à sociedade política - pode denotar mais uma expressão de desigualdade de gênero na participação institucional. A experiência e o aprendizado de homens nestes espaços torna possível a eles maior projeção a posições de liderança e representação que, fatalmente, lhes reservará maior destaque sociopolítico - o que pode ser muito importante para uma eventual disputa eleitoral no Legislativo ou Executivo no município ${ }^{8}$.

Vimos em Piracicaba, nas sete conferências realizadas na cidade em 2013, uma consistente vinculação entre a vida profissional das mulheres e sua participação em conferências de políticas públicas. Em grande parte, sobretudo nas conferências da Educação e da Assistência Social, a profissão é mediadora da participação feminina. Esta se legitima socialmente por sua profissão ou por um suposto pendor "natural" ao cuidado.

Também na Educação e na Assistência Social, a participação da sociedade civil parece ser menos desenvolvida e as conferências seguem sendo povoadas por profissionais e técnicos - também frequentemente ligados à atuação de entes públicos. Isto se vê menos nas conferências das Cidades, Meio Ambiente, Igualdade Racial, Esporte e Cultura, onde a sociedade civil interessada nestes temas se encontra mais organizada e em que mesmo a atuação profissional é permeada pela atuação em organizações da sociedade civil e/ou movimentos sociais.

Assim, há a menor participação das mulheres na sociedade civil e na sociedade política (partidos políticos), e também sua menor participação em conselhos e em conferências anteriores reforça as teses que denunciam o processo de exclusão sistemática de alguns grupos - mulheres e também pessoas negras e pobres - da democracia brasileira (Biroli 2016), e mesmo em processos que buscam promover democracia participativa. A maior dedicação da mulher a espaços do âmbito privado e íntimo (a casa, a igreja ou até mesmo a própria associação comunitária em seus fazeres cotidianos e não necessariamente ligados à representação política) deve-se à permanência de práticas de restrição à sua presença no espaço público. Tais práticas têm raízes e manifestações diversas, mas todas tornam muito mais difícil à mulher que ao homem o compromisso com cargos de direção e de maior visibilidade política, também na sociedade civil e também no nível local.

Entendemos que estes resultados - mesmo que obtidos em um estudo de caso único - podem ser significativos sobre o que se verifica em outros contextos sociopolíticos. Adicionada à literatura que analisamos, nossa pesquisa chama atenção para o fato de que as mulheres precisam vencer barreiras muito consistentes para participar, mesmo em processos locais. A dedicação profissional - e cotidiana - das mulheres aos setores ligados ao cuidado e a relativa pouca presença das mulheres no mundo associativo são fatores que não apenas estão correlacionados, mas que considerados em conjunto, potencializam o cerceamento das mulheres às instâncias de decisão política da sociedade brasileira.

A agenda de pesquisa e a agenda política aqui se articulam. É preciso ampliar o referencial teórico e analítico a respeito da exclusão das mulheres de instituições participativas. Este fenômeno está relacionado às práticas patriarcais e machistas que costumeiramente reservam às mulheres as bases das entidades associativas. Compreender os mecanismos de exclusão é fundamental para que possamos combatê-los. E, como pauta política, é preciso considerar que o reforço à democracia que as instituições participativas realizam não 
podem reproduzir exclusões de quaisquer natureza. As instituições participativas precisam ter como pauta central o combate a elas.

Wagner de Melo Romão (wromao@unicamp.br) é Doutor em Sociologia pela USP e professor do Departamento de Ciência Política da Unicamp.

Carla Gandini Giani Martelli (carla.martelli@ unesp.br) é Doutora cm Sociologia pela Unesp e professora do Departamento de Ciências Sociais da Unesp.

\section{Referências}

Alencar, J.; Cruxên, I.; Fonseca, I.; Pires, R. \& Ribeiro, U. (2013) Participação Social e Desigualdades nos Conselhos Nacionais. Sociologias, 15(32), pp. 112-146. DOI: 10.1590/S1517-45222013000100006

Almeida, C.; Lüchmann, L. \& Ribeiro, E. (2012) Associativismo e representação política feminina no Brasil. Revista Brasileira de Ciência Política, s/v(8), pp. 237-263. DOI: 10.1590/S0103-33522012000200009

Avelar, L. (2013) Movimentos, Redes, Feminismo de Estado: A Representação Extraparlamentar das Mulheres Brasileiras. Cadernos Adenauer, 14(3), pp. 71-87.

Avritzer, L. \& Souza, C. H. L. (orgs) (2013) Conferências Nacionais: atores, dinâmicas participativas e efetividade. Brasília: IPEA.

Avritzer, L. (2009) Participatory institutions in democratic Brazil. Baltimore: Johns Hopkins.

Benzécri, J. P. (1979) Sur le Calcul des taux d'inertie dans l'analyse d'un questionaire, Addendum et erratum à [BIN.MULT.], Cahiers de l'Analyse des Données 4(3), pp. 377-378.

Bezerra, C. P. (2020) Ideologia e governabilidade: as políticas participativas nos governo do PT. Tese de Doutorado. São Paulo: Universidade de São Paulo.

Biroli, F. (2016) Divisão Sexual do Trabalho e Democracia. Dados, 59(3), pp. 681- 719. DOI: 10.1590/00115258201690

Bohn, S. (2010) Feminismo Estatal sob a Presidência Lula: O Caso da Secretaria de Políticas para Mulheres. Revista Debates, 4(2), pp. 81-106. DOI: 10.22456/1982-5269.17439

Conway, M. (2001) Women and Political Participation. Political Science and Politics, 34(2), pp. 231-233. DOI: $10.1017 / \mathrm{S} 1049096501000385$

Côrtes, S. V. (2005) Fóruns participativos e governança: uma sistematização das contribuições da literatura. In: C. Lubambo., D. Coelho \& M. Melo (orgs) Desenho institucional e participação política: Experiências no Brasil contemporâneo. Petrópolis: Vozes, pp. 13-32.

Côrtes, S. V. (2011) As diferentes instituições participativas existentes nos municípios brasileiros. In: R. R. C. Pires (orgs) Efetividade das instituições participativas no Brasil: estratégias de avaliação. Brasília: IPEA, pp. 137-149. Disponível em: https://www.ipea.gov.br/portal/index.php?option=com_content\&view=article\&id=10761\&Itemid=2. Acesso em: 04 de fev. de 2021.

Cunha, E. S. M. (2013) Conferências de Políticas Públicas e inclusão participativa. In: L. Avritzer \& C. H. L. Souza (orgs) Conferências Nacionais: atores, dinâmicas participativas e efetividade. Brasília: IPEA, pp. 141-171.

Faria, C. F. \& Lins, I. L. (2017) Inclusão política? Recrutamento e seleção de atores nas conferências de políticas públicas. Opinião Pública, 23(3), p.580-611. DOI: 10.1590/1807-01912017233580

Faria, C. F., Silva, E. M. \& Lins, I. L. (2019) The dual nature of representative dynamics in Brazilian Public Policy Conferences: an analysis of the Conferences on Health, Social Assistent and Policy of Women. Representation, 55(3), pp.357-377. DOI: 10.1080/00344893.2019.1679239

Fiorina, M. (1999) A dark side of civic engagement. In: T. Skocpol \& M. Fiorina (eds) Civic engagement in American democracy. Washington: Brookings Institution Press, pp. 398-425.

Gohn, M. G. (2004) Sociedade civil no Brasil: movimentos sociais e ONGs. Revista Nómadas, s/v(20), pp. 140-151.

Greenacre, M. J. (1994). Multiple and Joint Correspondence Analysis. In: M. J. Greenacre \& J. Blasius (eds) Correspondence Analysis in the Social Sciences, London: Academic Press.

Halperin, S. \& Heath, O. (2012) Political research: methods and practical skills. New York: Oxford University Press.

Hirata, H. (2020) Comparando relações de cuidado: Brasil, França e Japão. Estudos Avançados, 34(98), pp. 25-40. DOI: 10.1590/s0103-4014.2020.3498.003.

Lovenduski, J. (2005) State Feminism and Political Representation. New York: Cambridge University Press.

Lüchmann, L. H. H. \& Almeida, C. (2010) A representação política das mulheres nos Conselhos Gestores de Políticas Públicas. Revista Katálysis, 13(1), pp. 86-94. DOI: 10.1590/S1414-49802010000100010

Lüchmann, L. H. H., Almeida, C. \& Gimenes, E. R., 2016. Gênero e Representação Política nos Conselhos Gestores no Brasil. Dados, 59(3), pp. 789-822. DOI: 10.1590/00115258201692

Marquetti, A. (2003) Participação e redistribuição: o orçamento participativo em Porto Alegre. In: L. Avritzer \& Z. Navarro (orgs) A inovação democrática no Brasil: o orçamento participativo. São Paulo: Cortez, pp. 129-156.

Martelli, C. G. (2015) Conferências Municipais: setores de políticas e a diversidade de seus participantes. In: Congress of the Latin American Studies Association, San Juan.

Martelli, C. G. \& Romão, W. (2016) Apoio e desenvolvimento ao Observatório Cidadão de Piracicaba: extensão, formação e cidadania. In: C. C. Paiva (orgs) Universidade e Sociedade: projetos de extensão da FCLAr-Unesp e suas ações transformadoras. São Paulo: Cultura Acadêmica, pp. 89-109. 
Morgado, R., Romão, W., Beitum, L. F. \& Palmieri, R. (2013) A contribuição do Observatório Cidadão de Piracicaba para a transparência pública e o acesso à informação no município. Revista de Administração Municipal, s/v(282), pp.48-60.

Petinelli, V. (2014) Uma análise dos condicionantes da capacidade de influência das conferências de políticas públicas sobre os programas das respectivas políticas setoriais: o caso da $1^{a} C A P, 1^{a}$ ConCidades, $1^{a} C M A, 1^{a} C E, 1^{a} C P M$ e $1^{a} C P I R$. Tese de Doutorado. Belo Horizonte: Universidade Federal de Minas Gerais.

Petinelli, V. (2017) A quem servem as conferências de políticas públicas? Desenho institucional e atores beneficiados. Opinião Pública, 23(3), pp. 612-646. DOI: 10.1590/1807-01912017233612

Phillips, A. (1991) Engendering Democracy. Cambridge: Polity.

Pinto, C. R. J. (2004) Espaços deliberativos e a questão da representação. Revista Brasileira de Ciências Sociais, 19(54), pp. 97-114. DOI: 10.1590/S0102-69092004000100006

Romão, W. (2011) Conselheiros do Orçamento Participativo nas franjas da sociedade política. Lua Nova, s/v(84), pp. $219-244$. DOI: 10.1590/S0102-64452011000300008

Santos, B. S. \& Avritzer, L. (2002) Para ampliar o cânone democrático. In: B. S. Santos (orgs) Democratizar a democracia: os caminhos da democracia participativa. Rio de Janeiro: Civilização Brasileira, pp. 39-82.

Santos, B. S. (1998) Participatory budgeting in Porto Alegre: toward a redistributive democracy. Politics \& Society, 26(8), pp. 461-510. DOI: 10.1177/0032329298026004003

Skocpol, T. \& Fiorina, M. (1999) Advocates without members: the recente transformation of American civic life. In: T. Skocpol \& M. Fiorina (eds) Civic engagement in American democracy. Washington: Brookings Institution Press, pp. 461-509.

Zaremberg, G. (2016) ¿Género versus Pueblo?: Movilización, Cooptación y Participación en Nicaragua, Venezuela, Brasil y México. Latin American Research Review, 51(1), pp. 84-108. DOI: 10.1353/lar.2016.0016

\section{Outras fontes}

Avelino, D. P. \& Goulin, L. V. (2018) Base de dados sobre conferências nacionais e um ensaio de análise lexical por contexto. [online] Brasília: IPEA, 142p. Disponível em: https://www.ipea.gov.br/portal/images/stories/PDFs/TDs/td_2374.pdf. Acesso em: 04 de fev. de 2021.

BRASIL. (2009) As conferências nacionais de saúde: evolução e perspectivas. Brasília: CONASS.

IPEA. (2013) Perfil dos conselheiros nacionais. Relatório de Pesquisa. Brasília: Instituto de Pesquisa Econômica Aplicada.

Gender and participation at the local level: study on municipal policy conferences

ABSTRACT Introduction: This article aims to discuss the participation of women in public policy conferences at the municipal level. Literature has pointed out that conferences are modalities of participation with the potential to reduce gender inequalities typical of traditional political institutions such as the Legislative Branch, at the three levels of government. However, even the conferences at their highest levels (national and state), seem to reproduce these same inequalities. We seek to understand the founding elements of this phenomenon by analyzing attributes of conference participants at the municipal level, focusing on the various sectors of public policy and the associative ties of these participants. Materials and methods: The empirical research focused on seven municipal conferences that took place in 2013 in the city of Piracicaba-SP, referring to the sectors of Education, Social Assistance, Cities, Environment, Culture, Racial Identity and Sports. Questionnaires were applied to the participants of these conferences, taking care not to include among these representatives of the local government. We obtained information about the respondent's socio-economic and political-institutional profile. Then, we proceed to the tabulation and statistical treatment of the data obtained, with a chi-square test of independence, to verify the existence of an association between the variables analyzed and the type of conference, and subsequent analysis of multiple correspondences, once that we wanted to assess the association between categorical variables. Results: There is a strong association between female participants and the Education and Social Assistance conferences. This result is related to the professional activity of women in these sectors, as teachers and social workers, reinforcing the thesis that considering the specificity of public policy areas is important for understanding the inclusive potential of women in conferences. In addition, the non-connection of women with non-governmental organizations, social movements, unions and political parties, as well as the non-participation in previous councils and conferences, was quite significant. Discussion: The participation of women in municipal conferences is strongly related to their professional activity. The low presence of women in institutions and movements that organize civil society, as well as in political parties - in comparison with men - are factors that are not only correlated, but that taken together, enhance the restriction of women's participation in the instances political decision-making by Brazilian society, including in spaces for institutional participation such as conferences, even at the local level.

KEYWORDS: policy conferences; gender; participation; civil society; local government.

This is an Open Access article distributed under the terms of the Creative Commons Attribution Non-Commercial License which permits unrestricted non-commercial use, distribution, and reproduction in any medium provided the original work is properly cited.

A produção desse manuscrito foi viabilizada através do patrocínio fornecido pelo Centro Universitário Internacional Uninter à Revista de Sociologia e Política. 


\section{Apêndice}

Tabela 1A - Caracterização da amostra de acordo com as variáveis analisadas

\begin{tabular}{|c|c|c|c|c|c|c|c|c|c|c|}
\hline & & $\begin{array}{c}\text { Geral } \\
(\mathrm{N}=\mathbf{4 0 7})\end{array}$ & $\begin{array}{l}\text { Assistência } \\
\text { Social } \\
(\mathrm{N}=47)\end{array}$ & $\begin{array}{l}\text { Cidades } \\
(\mathrm{N}=72)\end{array}$ & $\begin{array}{l}\text { Cultura } \\
(\mathrm{N}=27)\end{array}$ & $\begin{array}{l}\text { Educação } \\
(\mathbf{N}=\mathbf{8 8})\end{array}$ & $\begin{array}{l}\text { Esporte } \\
(\mathrm{N}=19)\end{array}$ & $\begin{array}{c}\text { Igualdade } \\
\text { Racial } \\
(\mathbf{N}=66)\end{array}$ & $\begin{array}{c}\text { Meio } \\
\text { Ambiente } \\
(\mathrm{N}=\mathbf{8 8})\end{array}$ & P-Valor \\
\hline \multirow[t]{3}{*}{ Gênero - $\mathrm{n}^{\circ} /$ total $\mathrm{n}^{\circ}(\%)$} & Masculino & $\begin{array}{c}147 / 407 \\
(36.12)\end{array}$ & $1 / 47(2.13)$ & $\begin{array}{c}42 / 72 \\
(58.33)\end{array}$ & $\begin{array}{c}14 / 27 \\
(51.85)\end{array}$ & $7 / 88(7.95)$ & $\begin{array}{c}12 / 19 \\
(63.16)\end{array}$ & $\begin{array}{c}34 / 66 \\
(51.52)\end{array}$ & $\begin{array}{c}37 / 88 \\
(42.05)\end{array}$ & $<0.0001$ \\
\hline & Feminino & $\begin{array}{c}256 / 407 \\
(62.90)\end{array}$ & $\begin{array}{c}45 / 47 \\
(95.74)\end{array}$ & $\begin{array}{c}27 / 72 \\
(37.50)\end{array}$ & $\begin{array}{c}13 / 27 \\
(48.15)\end{array}$ & $\begin{array}{c}81 / 88 \\
(92.05)\end{array}$ & $\begin{array}{c}7 / 19 \\
(36.84)\end{array}$ & $\begin{array}{c}32 / 66 \\
(48.48)\end{array}$ & $\begin{array}{c}51 / 88 \\
(57.95)\end{array}$ & \\
\hline & Sem informação & $\begin{array}{l}4 / 407 \\
(0.98)\end{array}$ & $1 / 47(2.13)$ & $\begin{array}{c}3 / 72 \\
(4.17)\end{array}$ & $\begin{array}{c}0 / 27 \\
(0.00)\end{array}$ & $0 / 88(0.00)$ & $\begin{array}{c}0 / 19 \\
(0.00)\end{array}$ & $0 / 66(0.00)$ & $\begin{array}{c}0 / 88 \\
(0.00)\end{array}$ & \\
\hline \multirow[t]{5}{*}{ Idade - $\mathrm{n}^{\circ} /$ total $\mathrm{n}^{\circ}(\%)$} & Até 27 anos & $\begin{array}{l}82 / 407 \\
(20.15)\end{array}$ & $\begin{array}{c}12 / 47 \\
(25.53)\end{array}$ & $\begin{array}{c}4 / 72 \\
(5.56)\end{array}$ & $\begin{array}{c}5 / 27 \\
(18.52)\end{array}$ & $\begin{array}{c}10 / 88 \\
(11.36)\end{array}$ & $\begin{array}{c}2 / 19 \\
(10.53)\end{array}$ & $\begin{array}{c}9 / 66 \\
(13.64)\end{array}$ & $\begin{array}{c}40 / 88 \\
(45.45)\end{array}$ & $<0.0001$ \\
\hline & Entre 27 e 40 anos & $\begin{array}{c}116 / 407 \\
(28.50)\end{array}$ & $\begin{array}{c}16 / 47 \\
(34.04)\end{array}$ & $\begin{array}{c}15 / 72 \\
(20.83)\end{array}$ & $\begin{array}{c}6 / 27 \\
(22.22)\end{array}$ & $\begin{array}{c}38 / 88 \\
(43.18)\end{array}$ & $\begin{array}{c}3 / 19 \\
(15.79)\end{array}$ & $\begin{array}{c}16 / 66 \\
(24.24)\end{array}$ & $\begin{array}{c}22 / 88 \\
(25.00)\end{array}$ & \\
\hline & Entre 40 e 53 anos & $\begin{array}{c}131 / 407 \\
(32.19)\end{array}$ & $\begin{array}{c}15 / 47 \\
(31.91)\end{array}$ & $\begin{array}{c}32 / 72 \\
(44.44)\end{array}$ & $\begin{array}{c}10 / 27 \\
(37.04)\end{array}$ & $\begin{array}{c}30 / 88 \\
(34.09)\end{array}$ & $\begin{array}{c}9 / 19 \\
(47.37)\end{array}$ & $\begin{array}{c}21 / 66 \\
(31.82)\end{array}$ & $\begin{array}{c}14 / 88 \\
(15.91)\end{array}$ & \\
\hline & Acima de 53 anos & $\begin{array}{l}70 / 407 \\
(17.20)\end{array}$ & $3 / 47(6.38)$ & $\begin{array}{c}20 / 72 \\
(27.78)\end{array}$ & $\begin{array}{c}6 / 27 \\
(22.22)\end{array}$ & $\begin{array}{c}9 / 88 \\
(10.23)\end{array}$ & $\begin{array}{c}4 / 19 \\
(21.05)\end{array}$ & $\begin{array}{c}19 / 66 \\
(28.79)\end{array}$ & $\begin{array}{c}9 / 88 \\
(10.23)\end{array}$ & \\
\hline & Sem informação & $\begin{array}{l}8 / 407 \\
(1.97)\end{array}$ & $1 / 47(2.13)$ & $\begin{array}{c}1 / 72 \\
(1.39)\end{array}$ & $\begin{array}{c}0 / 27 \\
(0.00)\end{array}$ & $1 / 88(1.14)$ & $\begin{array}{c}1 / 19 \\
(5.26)\end{array}$ & $1 / 66(1.52)$ & $\begin{array}{c}3 / 88 \\
(3.41)\end{array}$ & \\
\hline \multirow[t]{3}{*}{$\begin{array}{l}\text { Raça/cor }-\mathrm{n}^{\circ} / \text { total n}^{\circ} \\
(\%)\end{array}$} & Branco & $\begin{array}{c}271 / 407 \\
(66.58)\end{array}$ & $\begin{array}{c}33 / 47 \\
(70.21)\end{array}$ & $\begin{array}{c}50 / 72 \\
(69.44)\end{array}$ & $\begin{array}{c}15 / 27 \\
(55.56)\end{array}$ & $\begin{array}{c}72 / 88 \\
(81.82)\end{array}$ & $\begin{array}{c}16 / 19 \\
(84.21)\end{array}$ & $\begin{array}{c}12 / 66 \\
(18.18)\end{array}$ & $\begin{array}{c}73 / 88 \\
(82.95)\end{array}$ & $<0.0001$ \\
\hline & Pardo/preto & $\begin{array}{l}119 / 407 \\
(29.24)\end{array}$ & $\begin{array}{c}11 / 47 \\
(23.40)\end{array}$ & $\begin{array}{c}20 / 72 \\
(27.78)\end{array}$ & $\begin{array}{c}11 / 27 \\
(40.74)\end{array}$ & $\begin{array}{c}14 / 88 \\
(15.91)\end{array}$ & $\begin{array}{c}2 / 19 \\
(10.53)\end{array}$ & $\begin{array}{c}50 / 66 \\
(75.76)\end{array}$ & $\begin{array}{c}11 / 88 \\
(12.50)\end{array}$ & \\
\hline & Outro/sem informação & $\begin{array}{l}17 / 407 \\
(4.18)\end{array}$ & $3 / 47(6.38)$ & $\begin{array}{c}2 / 72 \\
(2.78)\end{array}$ & $\begin{array}{c}1 / 27 \\
(3.70)\end{array}$ & $2 / 88(2.27)$ & $\begin{array}{c}1 / 19 \\
(5.26)\end{array}$ & $4 / 66(6.06)$ & $\begin{array}{c}4 / 88 \\
(4.55)\end{array}$ & \\
\hline \multirow[t]{5}{*}{$\begin{array}{l}\text { Escolaridade }-\mathrm{n}^{\circ} / \text { total } \\
\mathrm{n}^{\circ}(\%)\end{array}$} & Ensino Fundamental & $\begin{array}{l}21 / 407 \\
(5.16)\end{array}$ & $2 / 47(4.26)$ & $\begin{array}{c}5 / 72 \\
(6.94)\end{array}$ & $\begin{array}{c}1 / 27 \\
(3.70)\end{array}$ & $3 / 88(3.41)$ & $\begin{array}{c}0 / 19 \\
(0.00)\end{array}$ & $\begin{array}{c}7 / 66 \\
(10.61)\end{array}$ & $\begin{array}{c}3 / 88 \\
(3.41)\end{array}$ & 0.0025 \\
\hline & Ensino Médio & $\begin{array}{l}56 / 407 \\
(13.76)\end{array}$ & $3 / 47(6.38)$ & $\begin{array}{c}15 / 72 \\
(20.83)\end{array}$ & $\begin{array}{c}6 / 27 \\
(22.22)\end{array}$ & $6 / 88(6.82)$ & $\begin{array}{c}1 / 19 \\
(5.26)\end{array}$ & $\begin{array}{c}17 / 66 \\
(25.76)\end{array}$ & $\begin{array}{c}8 / 88 \\
(9.09)\end{array}$ & \\
\hline & Ensino Superior & $\begin{array}{l}261 / 407 \\
(64.13)\end{array}$ & $\begin{array}{c}37 / 47 \\
(78.72)\end{array}$ & $\begin{array}{c}39 / 72 \\
(54.17)\end{array}$ & $\begin{array}{c}15 / 27 \\
(55.56)\end{array}$ & $\begin{array}{c}56 / 88 \\
(63.64)\end{array}$ & $\begin{array}{c}17 / 19 \\
(89.47)\end{array}$ & $\begin{array}{c}36 / 66 \\
(54.55)\end{array}$ & $\begin{array}{c}61 / 88 \\
(69.32)\end{array}$ & \\
\hline & Pós Graduação & $\begin{array}{l}63 / 407 \\
(15.48)\end{array}$ & $3 / 47(6.38)$ & $\begin{array}{c}12 / 72 \\
(16.67)\end{array}$ & $\begin{array}{c}5 / 27 \\
(18.52)\end{array}$ & $\begin{array}{c}23 / 88 \\
(26.14)\end{array}$ & $\begin{array}{c}1 / 19 \\
(5.26)\end{array}$ & $6 / 66(9.09)$ & $\begin{array}{c}13 / 88 \\
(14.77)\end{array}$ & \\
\hline & Sem informação & $\begin{array}{l}6 / 407 \\
(1.47)\end{array}$ & $2 / 47(4.26)$ & $\begin{array}{c}1 / 72 \\
(1.39)\end{array}$ & $\begin{array}{c}0 / 27 \\
(0.00)\end{array}$ & $0 / 88(0.00)$ & $\begin{array}{c}0 / 19 \\
(0.00)\end{array}$ & $0 / 66(0.00)$ & $\begin{array}{c}3 / 88 \\
(3.41)\end{array}$ & \\
\hline \multirow[t]{5}{*}{ Renda - $\mathrm{n}^{\circ} /$ total $\mathrm{n}^{\circ}(\%)$} & Até 3 salários & $\begin{array}{l}77 / 407 \\
(18.92)\end{array}$ & $8 / 47(17.02)$ & $\begin{array}{c}13 / 72 \\
(18.06)\end{array}$ & $\begin{array}{c}7 / 27 \\
(25.93)\end{array}$ & $7 / 88(7.95)$ & $\begin{array}{c}3 / 19 \\
(15.79)\end{array}$ & $\begin{array}{c}20 / 66 \\
(30.30)\end{array}$ & $\begin{array}{c}19 / 88 \\
(21.59)\end{array}$ & 0.0807 \\
\hline & Entre 3 e 5 salários & $\begin{array}{l}94 / 407 \\
(23.10)\end{array}$ & $\begin{array}{c}11 / 47 \\
(23.40)\end{array}$ & $\begin{array}{c}11 / 72 \\
(15.28)\end{array}$ & $\begin{array}{c}6 / 27 \\
(22.22)\end{array}$ & $\begin{array}{c}23 / 88 \\
(26.14)\end{array}$ & $\begin{array}{c}2 / 19 \\
(10.53)\end{array}$ & $\begin{array}{c}20 / 66 \\
(30.30)\end{array}$ & $\begin{array}{c}21 / 88 \\
(23.86)\end{array}$ & \\
\hline & Entre 5 e 10 salários & $\begin{array}{l}105 / 407 \\
(25.80)\end{array}$ & $\begin{array}{c}13 / 47 \\
(27.66)\end{array}$ & $\begin{array}{c}21 / 72 \\
(29.17)\end{array}$ & $\begin{array}{c}6 / 27 \\
(22.22)\end{array}$ & $\begin{array}{c}25 / 88 \\
(28.41)\end{array}$ & $\begin{array}{c}6 / 19 \\
(31.58)\end{array}$ & $\begin{array}{c}13 / 66 \\
(19.70)\end{array}$ & $\begin{array}{c}21 / 88 \\
(23.86)\end{array}$ & \\
\hline & Acima de 10 salários & $\begin{array}{l}49 / 407 \\
(12.04)\end{array}$ & $1 / 47(2.13)$ & $\begin{array}{c}11 / 72 \\
(15.28)\end{array}$ & $\begin{array}{c}3 / 27 \\
(11.11)\end{array}$ & $\begin{array}{c}10 / 88 \\
(11.36)\end{array}$ & $\begin{array}{c}4 / 19 \\
(21.05)\end{array}$ & $\begin{array}{c}8 / 66 \\
(12.12)\end{array}$ & $\begin{array}{c}12 / 88 \\
(13.64)\end{array}$ & \\
\hline & Sem informação & $\begin{array}{l}82 / 407 \\
(20.15)\end{array}$ & $\begin{array}{c}14 / 47 \\
(29.79)\end{array}$ & $\begin{array}{c}16 / 72 \\
(22.22)\end{array}$ & $\begin{array}{c}5 / 27 \\
(18.52)\end{array}$ & $\begin{array}{c}23 / 88 \\
(26.14)\end{array}$ & $\begin{array}{c}4 / 19 \\
(21.05)\end{array}$ & $5 / 66(7.58)$ & $\begin{array}{c}15 / 88 \\
(17.05)\end{array}$ & \\
\hline \multirow{2}{*}{$\begin{array}{l}\text { Vínculo a } \\
\text { ONG/entidade - } \mathrm{n}^{\circ} / \text { total } \\
\mathrm{n}^{\circ}(\%)\end{array}$} & Sim & $\begin{array}{l}122 / 407 \\
(29.98)\end{array}$ & $\begin{array}{c}12 / 47 \\
(25.53)\end{array}$ & $\begin{array}{c}32 / 72 \\
(44.44)\end{array}$ & $\begin{array}{c}10 / 27 \\
(37.04)\end{array}$ & $5 / 88(5.68)$ & $\begin{array}{c}10 / 19 \\
(52.63)\end{array}$ & $\begin{array}{c}25 / 66 \\
(37.88)\end{array}$ & $\begin{array}{c}25 / 88 \\
(28.41)\end{array}$ & $<0.0001$ \\
\hline & Não & $\begin{array}{c}285 / 407 \\
(70.02)\end{array}$ & $\begin{array}{c}35 / 47 \\
(74.46)\end{array}$ & $\begin{array}{c}40 / 72 \\
(55.56)\end{array}$ & $\begin{array}{c}17 / 27 \\
(62.96)\end{array}$ & $\begin{array}{c}83 / 88 \\
(94.32)\end{array}$ & $\begin{array}{c}9 / 19 \\
(47.37)\end{array}$ & $\begin{array}{c}41 / 66 \\
(62.12)\end{array}$ & $\begin{array}{c}63 / 88 \\
(71.59)\end{array}$ & \\
\hline \multirow[t]{2}{*}{$\begin{array}{l}\text { Vínculo a movimentos } \\
\text { sociais - } \mathrm{n}^{\circ} / \text { total } \mathrm{n}^{\circ}(\%)\end{array}$} & Sim & $\begin{array}{l}80 / 407 \\
(19.66)\end{array}$ & $0 / 47(0.00)$ & $\begin{array}{c}23 / 72 \\
(31.94)\end{array}$ & $\begin{array}{c}16 / 27 \\
(59.26)\end{array}$ & $6 / 88(6.82)$ & $\begin{array}{c}3 / 19 \\
(15.79)\end{array}$ & $\begin{array}{c}16 / 66 \\
(24.24)\end{array}$ & $\begin{array}{c}16 / 88 \\
(18.18)\end{array}$ & $<0.0001$ \\
\hline & Não & $\begin{array}{l}327 / 407 \\
(80.34)\end{array}$ & $\begin{array}{c}47 / 47 \\
(100.00)\end{array}$ & $\begin{array}{c}49 / 72 \\
(68.06)\end{array}$ & $\begin{array}{c}11 / 27 \\
(40.74)\end{array}$ & $\begin{array}{c}82 / 88 \\
(93.18)\end{array}$ & $\begin{array}{c}16 / 19 \\
(84.21)\end{array}$ & $\begin{array}{c}50 / 66 \\
(75.76)\end{array}$ & $\begin{array}{c}72 / 88 \\
(81.82)\end{array}$ & \\
\hline \multirow[t]{2}{*}{$\begin{array}{l}\text { Filiação partidária - } \\
\mathrm{n}^{\circ} / \text { total }^{\circ}(\%)\end{array}$} & Sim & $\begin{array}{l}61 / 407 \\
(14.99)\end{array}$ & $1 / 47(2.13)$ & $\begin{array}{c}25 / 72 \\
(34.72)\end{array}$ & $\begin{array}{c}3 / 27 \\
(11.11)\end{array}$ & $2 / 88(2.27)$ & $\begin{array}{c}7 / 19 \\
(36.84)\end{array}$ & $\begin{array}{c}20 / 66 \\
(30.30)\end{array}$ & $\begin{array}{c}3 / 88 \\
(3.41)\end{array}$ & $<0.0001$ \\
\hline & Não & $\begin{array}{l}346 / 407 \\
(85.01)\end{array}$ & $\begin{array}{c}46 / 47 \\
(97.87)\end{array}$ & $\begin{array}{c}47 / 72 \\
(65.28)\end{array}$ & $\begin{array}{c}24 / 27 \\
(88.89)\end{array}$ & $\begin{array}{c}86 / 88 \\
(97.73)\end{array}$ & $\begin{array}{c}12 / 19 \\
(63.16)\end{array}$ & $\begin{array}{c}46 / 66 \\
(69.70)\end{array}$ & $\begin{array}{c}85 / 88 \\
(96.59)\end{array}$ & \\
\hline \multirow[t]{2}{*}{$\begin{array}{l}\text { Vínculo a sindicato - } \\
\mathrm{n}^{\circ} / \text { total } \mathrm{n}^{\circ}(\%)\end{array}$} & Sim & $\begin{array}{l}104 / 407 \\
(25.55)\end{array}$ & $4 / 47(8.51)$ & $\begin{array}{c}32 / 72 \\
(44.44)\end{array}$ & $\begin{array}{c}7 / 27 \\
(25.93)\end{array}$ & $\begin{array}{c}23 / 88 \\
(26.14)\end{array}$ & $\begin{array}{c}4 / 19 \\
(21.05)\end{array}$ & $\begin{array}{c}26 / 66 \\
(39.39)\end{array}$ & $\begin{array}{c}8 / 88 \\
(9.09)\end{array}$ & $<0.0001$ \\
\hline & Não & $\begin{array}{l}303 / 407 \\
(74.45)\end{array}$ & $\begin{array}{c}43 / 47 \\
(91.49)\end{array}$ & $\begin{array}{c}40 / 72 \\
(55.56)\end{array}$ & $\begin{array}{c}20 / 27 \\
(74.07)\end{array}$ & $\begin{array}{c}65 / 88 \\
(73.86)\end{array}$ & $\begin{array}{c}15 / 19 \\
(78.95)\end{array}$ & $\begin{array}{c}40 / 66 \\
(60.61)\end{array}$ & $\begin{array}{c}80 / 88 \\
(90.91)\end{array}$ & \\
\hline
\end{tabular}




\begin{tabular}{|c|c|c|c|c|c|c|c|c|c|c|}
\hline & & $\begin{array}{c}\text { Geral } \\
(\mathrm{N}=\mathbf{4 0 7})\end{array}$ & $\begin{array}{l}\text { Assistência } \\
\text { Social } \\
(\mathbf{N}=47)\end{array}$ & $\begin{array}{l}\text { Cidades } \\
(\mathrm{N}=72)\end{array}$ & $\begin{array}{l}\text { Cultura } \\
(\mathrm{N}=27)\end{array}$ & $\begin{array}{l}\text { Educação } \\
(\mathbf{N}=\mathbf{8 8})\end{array}$ & $\begin{array}{l}\text { Esporte } \\
(\mathrm{N}=19)\end{array}$ & $\begin{array}{l}\text { Igualdade } \\
\text { Racial } \\
(\mathbf{N}=66)\end{array}$ & $\begin{array}{c}\text { Meio } \\
\text { Ambiente } \\
(\mathbf{N}=\mathbf{8 8})\end{array}$ & P-Valor \\
\hline \multirow{2}{*}{$\begin{array}{l}\text { Participação em } \\
\text { conselhos - } \mathrm{n}^{\circ} / \text { total } \mathrm{n}^{\circ} \\
(\%)\end{array}$} & Sim & $\begin{array}{c}133 / 407 \\
(32.68)\end{array}$ & $\begin{array}{c}12 / 47 \\
(25.53)\end{array}$ & $\begin{array}{c}27 / 72 \\
(37.50)\end{array}$ & $\begin{array}{c}8 / 27 \\
(29.63)\end{array}$ & $\begin{array}{c}35 / 88 \\
(39.77)\end{array}$ & $\begin{array}{c}10 / 19 \\
(52.63)\end{array}$ & $\begin{array}{c}25 / 66 \\
(37.88)\end{array}$ & $\begin{array}{c}16 / 88 \\
(18.18)\end{array}$ & 0.0092 \\
\hline & Não & $\begin{array}{c}274 / 407 \\
(67.32)\end{array}$ & $\begin{array}{c}35 / 47 \\
(74.47)\end{array}$ & $\begin{array}{c}45 / 72 \\
(62.50)\end{array}$ & $\begin{array}{c}19 / 27 \\
(70.37)\end{array}$ & $\begin{array}{c}53 / 88 \\
(60.23)\end{array}$ & $\begin{array}{c}9 / 19 \\
(47.37)\end{array}$ & $\begin{array}{c}41 / 66 \\
(62.12)\end{array}$ & $\begin{array}{c}72 / 88 \\
(81.82)\end{array}$ & \\
\hline \multirow{2}{*}{$\begin{array}{l}\text { Participação em outras } \\
\text { conferências - } \mathrm{n}^{\circ} . / \text { total } \\
\mathrm{n}^{\circ}(\%)\end{array}$} & Sim & $\begin{array}{l}177 / 407 \\
(43.49)\end{array}$ & $\begin{array}{c}26 / 47 \\
(55.32)\end{array}$ & $\begin{array}{c}35 / 72 \\
(48.61)\end{array}$ & $\begin{array}{c}12 / 27 \\
(44.44)\end{array}$ & $\begin{array}{c}35 / 88 \\
(39.77)\end{array}$ & $\begin{array}{c}9 / 19 \\
(47.37)\end{array}$ & $\begin{array}{c}36 / 66 \\
(54.55)\end{array}$ & $\begin{array}{c}24 / 88 \\
(27.27)\end{array}$ & 0.009 \\
\hline & Não & $\begin{array}{c}230 / 407 \\
(56.51)\end{array}$ & $\begin{array}{c}21 / 47 \\
(44.68) \\
\end{array}$ & $\begin{array}{c}37 / 72 \\
(51.39)\end{array}$ & $\begin{array}{c}15 / 27 \\
(55.56)\end{array}$ & $\begin{array}{c}53 / 88 \\
(60.23) \\
\end{array}$ & $\begin{array}{c}10 / 19 \\
(52.63)\end{array}$ & $\begin{array}{c}30 / 66 \\
(45.45) \\
\end{array}$ & $\begin{array}{c}64 / 88 \\
(72.73) \\
\end{array}$ & \\
\hline
\end{tabular}

Fonte: Elaboração própria.

Tabela 2A - Resultados da análise de correspondência múltipla da tabela de Burt: inércia ajustada (correção de Benzécri) e porcentagens explicada e acumulada

\begin{tabular}{lccc}
\hline Dimensão & Inércia Ajustada & \% & \% Acumulada \\
\hline 1 & 0,0238 & 55,9 & 55,9 \\
2 & 0,0052 & 12,3 & 68,2 \\
3 & 0,0031 & 7,4 & 75,5 \\
4 & 0,0006 & 1,6 & 77,1 \\
5 & 0,0004 & 0,9 & 78,1 \\
6 & 0,0001 & 0,3 & 78,3 \\
7 & 0,0001 & 0,3 & 78,6 \\
8 & 0 & 0 & 78,6 \\
\hline
\end{tabular}

Fonte: Elaboração própria.

Tabela 3A - Coordenada de cada classe em cada dimensão

\begin{tabular}{lccc}
\hline Variável & Categoria & Dimensão 1 & Dimensão 2 \\
\hline Conferência & Assistência Social & $-0,2219$ & 0,0719 \\
& Cidades & 0,2651 & 0,0679 \\
& Cultura & 0,1658 & $-0,131$ \\
& Educação & $-0,2273$ & 0,1535 \\
Eexporte & Igualdade Racial & 0,2024 & 0,1421 \\
Meio Ambiente & Feminino & 0,3074 & $-0,1183$ \\
Idade & Masculino & $-0,2025$ & $-0,1494$ \\
& Acima de 53 & $-0,1104$ & 0,0255 \\
& Até 27 & 0,1915 & $-0,0442$ \\
Renda & Entre 27 e 40 & 0,2954 & 0 \\
& Entre 40 e 53 & $-0,2478$ & $-0,1773$ \\
& Não & $-0,0941$ & 0,0339 \\
& Sim & 0,079 & 0,0757 \\
& Acima de 10 SM & 0,2101 & $-0,1656$
\end{tabular}




\begin{tabular}{lccc}
\hline Variável & Categoria & Dimensão 1 & Dimensão 2 \\
\hline \multirow{4}{*}{ Raça - Branca } & Entre 5 e 10 SM & 0,0343 & 0,1177 \\
& NR & $-0,0917$ & 0,0422 \\
Ong & Não & 0,201 & $-0,0933$ \\
\multirow{3}{*}{ Movimento Social } & Sim & $-0,0967$ & 0,0449 \\
\multirow{4}{*}{ Partido Político } & Não & $-0,1054$ & 0,0204 \\
& Sim & 0,2439 & $-0,0473$ \\
Sindicalizado & Não & $-0,0764$ & 0,0182 \\
\multirow{3}{*}{ Conselho } & Sim & 0,3018 & $-0,0722$ \\
& Não & $-0,0816$ & $-0,0094$ \\
Outras Conferências & Sim & 0,4688 & 0,0541 \\
& Não & $-0,0899$ & $-0,0319$ \\
& Sim & 0,2549 & 0,0906 \\
& Não & $-0,0731$ & $-0,0579$ \\
& Sim & 0,1468 & 0,1162 \\
& Não & $-0,1251$ & $-0,0593$ \\
& Sim & 0,1593 & 0,0755 \\
\hline
\end{tabular}

Fonte: Elaboração própria. 